\title{
Rhamnolipids: solution against Aedes aegypti?
}

\author{
Vinicius L. Silva ${ }^{1}$, Roberta B. Lovaglio ${ }^{1}$, Claudio J. Von Zuben ${ }^{2}$ and Jonas Contiero ${ }^{1}$ * \\ ' Biochemistry and Microbiology, Universidade Estadual Paulista Júlio de Mesquita Filho, Rio Claro, Brazil \\ 2 Zoology and Entomology, Universidade Estadual Paulista Júlio de Mesquita Filho, Rio Claro, Brazil
}

\section{Edited by:}

Pattanathu K. S. M. Rahman, Teesside

University, UK

\section{Reviewed by:}

Lahondère Chloé, University of Washington, USA

Mani Kannan, Bharathidasan

University, India

\section{*Correspondence:}

Jonas Contiero, Biochemistry and

Microbiology, Universidade Estadual Paulista Júlio de Mesquita Filho,

Avenue 24A 1515 Bairro Bela Vista,

Rio Claro, 13506900 Sao Paulo, Brazil

e-mail: jconti@rc.unesp.br
Aedes aegypti mosquitoes are the primary transmitters of dengue fever, urban yellow fever, and chikungunya viruses. This mosquito has developed resistance to the insecticides currently used to control their populations. These chemical insecticides are harmful to the environment and can have negative effects on human health. Rhamnolipids are environmentally compatible biological surfactants, but their insecticidal activity has not been extensively studied. The present study evaluated the potential larvicidal, insecticidal, and repellent activities of rhamnolipids against $A$. aegypti. At concentrations of 800,900 , and $1000 \mathrm{mg} / \mathrm{L}$, rhamnolipids eliminated all mosquito larvae in $18 \mathrm{~h}$ and killed $100 \%$ of adults at $1000 \mathrm{mg} / \mathrm{L}$. According to the results it may be conclude that rhamnolipids should be applied to control larvae and mosquitos besides present the repellency activity against A. aegypti.

Keywords: biosurfactant, entomology, Pseudomonas aeruginosa, tropical diseases, repellent

\section{INTRODUCTION}

Rhamnolipids are biological surfactants that exhibit low toxicity and high biodegradability with few adverse effects on the environment. Environmental compatibility associated with the use of renewable carbon sources and production by microorganisms makes these compounds excellent substitutes for chemical surfactants given that both have similar physico-chemical properties (Desai and Banat, 1997; Banat et al., 2000; Rahman et al., 2010; Sekhon Randhawa and Rahman, 2014). Due to their capacity to reduce surface and interfacial tension, application of these microbial compounds in a broad range of industrial sectors has been proven and new applications have been evaluated (Rahman and Gakpe, 2008; Vatsa et al., 2010).

Kim et al. (2011) demonstrated the potential of rhamnolipids produced by Pseudomonas aeruginosa as an insecticide against aphids. These microbial metabolites are also efficient against Rhyzopertha dominica, a beetle species that attacks stored grains (Kamal et al., 2012). Biosurfactants produced by microbes can be used to control pests (Awada et al., 2005).

Substitution of insecticides by compounds with low toxicities such as rhamnolipids may contribute to reduced environmental and social impacts compared to chemicals. Furthermore, these compounds are an alternative to resistance developed by a significant number of arbovirus vectors (arthropod-borne viruses).

Aedes aegypti is anthropophilic and endophilic mosquito species. The larvae use tracheal breathing, and their respiratory siphon is located at the posterior of their body. For gas exchange, they must remain in an angle close to $90^{\circ}$ with the surface of the water $\left( \pm 20^{\circ}\right)$ depending on larval stage (Christophers, 1960).

This culicid species is of significant medical importance because it is the primary vector of urban yellow fever, dengue fever and chikungunya (Eldridge, 2005; Vontas et al., 2012).

According to Tsai et al. (2013), 40\% of the worldwide population is at risk of contracting dengue fever, rendering this disease one of the main arboviruses transmitted from mosquitoes to humans. An estimated 50-100 million cases of dengue fever occur worldwide per year (Kroeger and Nathan, 2006; Kourí et al., 2007; Garelli et al., 2013). These viruses are responsible for 30,000 deaths per year (World Health Organization, 2009).

Due to globalization, rampant population growth and climate change, it is likely that areas previously not know for dengue fever may become suitable sites for disease occurrence. After more than a half-century without a dengue outbreak in the United States, there have been recent outbreaks in Texas (2004-2005) and Florida (2009-2011) (Eisen and Moore, 2013). Rogers et al. (2014) reported a risk of dengue in some areas of Europe.

The use of chemical insecticides to control insect vectors is contrary to the recent global focus on developing products with low environmental impacts. Although population control is currently achieved using temephos for larvae and pyrethroids for adult mosquitoes (Chavasse and Yap, 1997), resistance to these compounds has been observed.

Potential negative effects of using chemical insecticides have led to research and development of products that are less harmful to the environment (Mittal, 2003). Biological pesticides produced by bacteria are effective against mosquitoes at low doses and do not affect other biological control agents (Walton and Mulla, 1992). This study evaluated the larvicidal, insecticidal, and repellent activities of rhamnolipids to verify their potential use as substitutes for insecticides that are currently used for A. aegypti control.

\section{MATERIALS AND METHODS RHAMNOLIPIDS PRODUCTION}

The $P$. aeruginosa strain LBI $2 \mathrm{~A} 1$ was used to produce rhamnolipids. Culture media and growth conditions were previously described by Müller et al. (2010). Fermentation using sunflower oil as a carbon source was performed in a bioreactor. Rhamnolipids isolated from sunflower oil were used in the experiments. 


\section{RHAMNOLIPIDS EXTRACTION}

Fermented broth was centrifuged at $4000 \mathrm{rpm}$ for $30 \mathrm{~min}$, and equal volumes of cell-free supernatant and n-hexane were thoroughly mixed in a volumetric flask. The mixture was then allowed to settle until the organic and aqueous phases separated. The organic phase was removed and $85 \% \mathrm{H}_{3} \mathrm{PO}_{4}$ 1:100 (v/v) was added to the aqueous phase to precipitate rhamnolipids. Biosurfactants were extracted with ethyl acetate $1: 1.25(\mathrm{v} / \mathrm{v})$. The mixture was shaken for $10 \mathrm{~min}$, allowed to settle, and the upper phase was removed. This extraction process was repeated using the lower phase extract. Extracted rhamnolipids were concentrated using a rotary evaporator, and the viscous yellowish product was dissolved in methanol and concentrated again by evaporation of residual solvent at $45^{\circ} \mathrm{C}$.

\section{STATISTICAL ANALYSIS}

Data were compared by one-way analysis of variance followed by quadratic regression test when significant differences were found at $P=0.05$ (Sokal and Rohlf, 1995). The software used was Sisvar 5.3.

\section{MOSOUITO AND LARVAL MAINTENANCE}

The Center of Zoonosis Control (Santa Bárbara D’Oeste, São Paulo, Brazil) provided the parental A. aegypti specimens. The mosquitoes were maintained in plastic cages in a room with controlled temperature at $27 \pm 2^{\circ} \mathrm{C}$ and a photoperiod of $12 \mathrm{~h}$. Adults were fed $10 \%$ glucose w/v.

For egg and larval acquisitions, blood feeding was performed using a laboratory mouse sedated with ketamine (approved by the Ethics Committee on Animal Use, Protocol $n^{\circ}$ : 3698, Decision from CEUA $N^{\circ}$ 022/2011). After the blood feeding, $600 \mathrm{ml}$ flasks with $300 \mathrm{ml}$ of mineral water were placed in the cages. A $12 \times 4 \mathrm{~cm}$ wood palette was used for oviposition. Flasks were filled with water until eggs were submerged. Larval feeding was performed with fish food (Löwenberg Neto and Navarro-Silva, 2004).

\section{LARVICIDAL EVALUATION}

A total of $40 \mathrm{ml}$ of either rhamnolipids or control solution with 10 A. aegypti larvae in the third instar of development were added to $60 \mathrm{ml}$ flasks. Small holes in the flask caps allowed for gas exchange. Control (mineral water) and solutions containing 50, 100, 200, 300, 400, 600, 800, 900, and $1000 \mathrm{mg} / \mathrm{L}$ rhamnolipids were evaluated. Experiments were performed in duplicate. Larvicidal activity was quantified based on time of permanence at the surface and the bottom and the numbers of attempts to stay on the surface, these factors were quantified in real time observations at intervals of 3 or $6 \mathrm{~h}$. The larvae were considered dead when they did not show any sign of activity and movement for more than $3 \mathrm{~h}$.

\section{REPELLENCY EVALUATION}

The following rhamnolipids concentrations, which demonstrated optimal performance in larvicidal evaluation, were used to evaluate repellency: 400, 800, and $1000 \mathrm{mg} / \mathrm{L}$. Mice were sprayed with $2,400 \mu \mathrm{L}$ of the solutions and labeled according to the type of treatment. Each cage contained a mouse for each treatment and a total of 25 mosquitoes, with an observation time of $40 \mathrm{~min}$. The number of mosquitoes that landed on each mouse was counted as host attraction. Tests were performed four times, and the mosquitoes' activity was quantified in real time by the researchers.

\section{INSECTICIDAL EVALUATION}

The concentrations evaluated for insecticidal activity were the same as in the repellency test. Experiments were conducted in triplicate, with each cage containing 20 mosquitoes and was sprayed whit 3,200 $\mu \mathrm{L}$ of rhamnolipids solution. Dead mosquitoes from each treatment were chosen randomly, for analysis in optical microscopy.

\section{RESULTS}

\section{LARVICIDAL ACTIVITY}

Larvicidal activity was observed at all rhamnolipids concentrations evaluated, with a minimum mortality rate of $50 \%$. Rhamnolipids concentrations of 800,900 , and $1000 \mathrm{mg} / \mathrm{L}$ killed all larvae at $18 \mathrm{~h}$ $\left(P=0.00 ; R^{2}=0.92\right)$, while 400 and $600 \mathrm{mg} / \mathrm{L}$ solutions required exposure for $48 \mathrm{~h}$ to reach $100 \%$ mortality $\left(P=0.00 ; R^{2}=0.86\right.$; Figure 1).

To evaluate if larvicidal activity was related to a reduction in surface tension and respiratory activity of the larvae, the residence time on the surface and the number of unsuccessful attempts to remain at the interface of the water surface were quantified (Figure 2A).

In solutions containing 50 and $100 \mathrm{mg} / \mathrm{L}$ rhamnolipids, larvae tended to stay longer on the surface compared to the control treatment. However, the larvae required more than one attempt to remain on the surface in the correct position to perform gas exchange (Figure 2B).

At concentrations greater than $400 \mathrm{mg} / \mathrm{L}$, length of time on the surface was shorter than observed in controls. The number of attempts to settle on the surface increased proportionally to rhamnolipids concentration.

To verify the loss of larval activity over time, the time of larval permanence at the bottom of the flask was quantified (Figure 3 ).

Larvae in the control group had the lowest length of time at the bottom of the flask, with an average of $30.6 \mathrm{~s}$. At concentrations of 800-1000 mg/L, the hydrostatic balance was broken between the

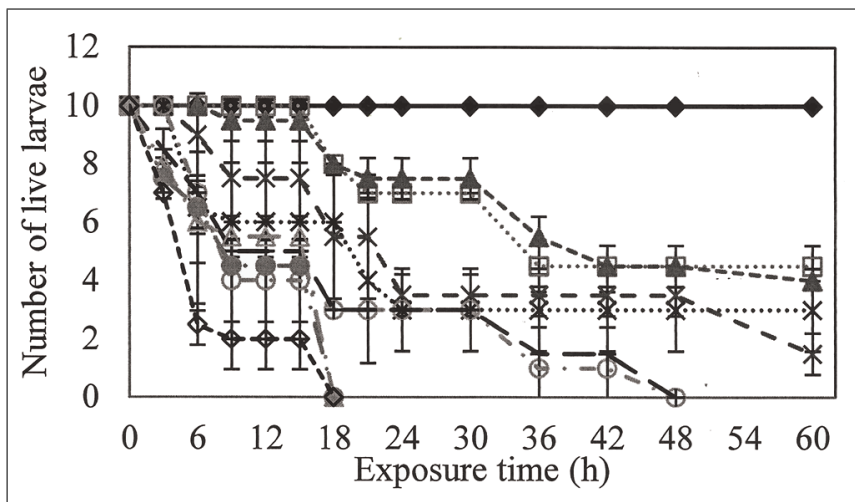

FIGURE 1 | Number of live larvae over time when exposed to different concentrations of rhamnolipids. Ten larvae of Aedes aegypti were exposed to: Control (_), 50(- অ), 100( $\neq-), 200(-x-), 300(* *), 400(-0)$, $600(+-), 800(\Rightarrow), 900(-)$ e 1000(-๑-) mg/L of rhamnolipids. 


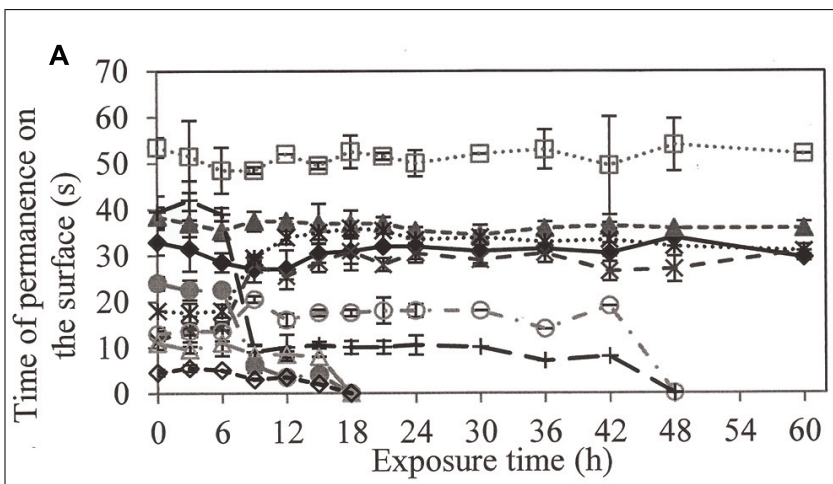

B

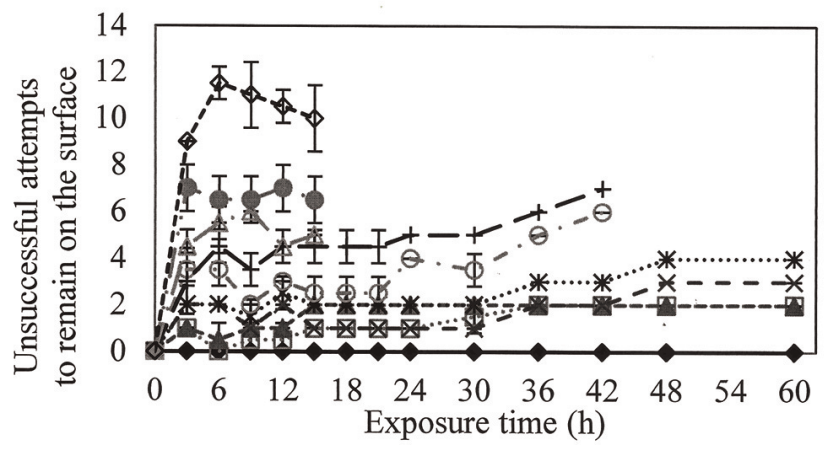

FIGURE 2 | (A) Time of permanence on the surface of the larvae to perform the gas exchange and (B) Number of unsuccessful attempts of the larvae in remain on the surface, when in contact with different solutions of

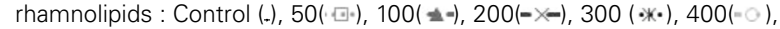
$600(+-), 800(=)$, $900(-$ ) e 1000(-\$-) mg/L of rhamnolipids.

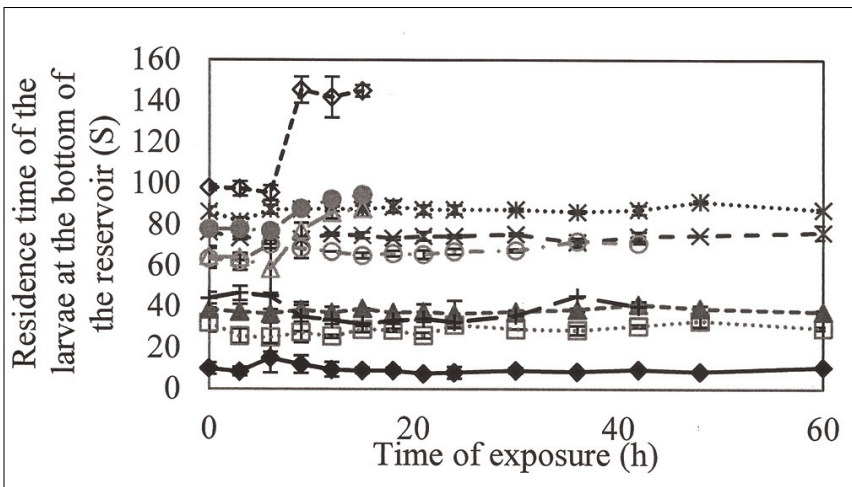

FIGURE 3 | Time that the $A$. aegypti larvae remained in the bottom of the reservoir along the time when exposed to different concentrations of rhamnolipids: Control (.), 50( -$), 100( \pm-), 200(-\times-), 300(* * \cdot)$, 400(- ) $600(+-\cdot), 800(-), 900(-\odot)$ e $1000(\cdot--) \mathrm{mg} / \mathrm{L}$ of rhamnolipids.

water and larvae, as evidenced by an increase in the length of time at the bottom, culminating in death after $18 \mathrm{~h}$.

\section{REPELLENCY}

The repellent property of rhamnolipids produced by $P$. aeruginosa was demonstrated given that mosquitoes had a higher incidence of landing on mice in the control group. The host attraction attempts

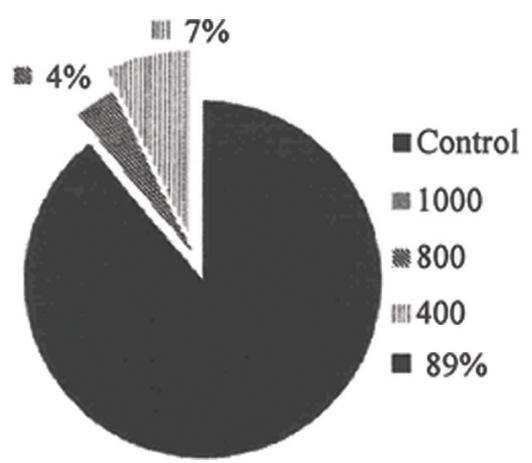

FIGURE 4 | Percentage of mosquitoes that landed on the mice and practiced hematophagy, subjected to different solutions of rhamnolipids: Control, 400, 800 e $1000 \mathrm{mg} / \mathrm{L}$ of rhamnolipids $(P=\mathbf{0 . 0 0}$; $R^{2}=0.97$; all concentrations evaluated were significantly different at $P=0.05$ ).

were reduced with increased concentrations of the biosurfactant (Figure 4).

Another factor evaluated was the time spent feeding by mosquitoes at different rhamnolipids concentrations (Table 1).

According to the results, the microbial metabolite produced by $P$. aeruginosa appears to reduce the residence time spent by mosquitoes in addition to reducing the total number of mosquitoes.

\section{Insecticidal effects}

The insecticidal activity of rhamnolipids against mosquitoes showed a $100 \%$ elimination of adults at the highest concentration evaluated compared to only $8 \%$ in the control group (Table 2 ).

Rhamnolipids are thought to disrupt the cuticle of the mosquito, as shown in Figure 5.

\section{DISCUSSION}

The rhamnolipids solutions evaluated in this study have surface tension values ranging between 31.4 and $38.7 \mathrm{mNm}^{-1}$. As a result, the larvae experience difficulties at the water/air interface, which reduces their respiratory efficiency and increases the number of attempts to stay at the surface. Lack of maintaining the correct

Table 1 | Average time of hematophagy on mice treated with different rhamnolipids concentrations: control, 400,800 , and $1000 \mathrm{mg} / \mathrm{L}$ $\left(P=0.00 ; R^{2}=0.99\right)$.

\begin{tabular}{lcc}
\hline $\begin{array}{l}\text { Rhamnolipids } \\
\text { concentration }\left(\mathbf{m g . L}^{\mathbf{- 1}}\right)\end{array}$ & $\begin{array}{c}\text { Average length of stay } \\
\text { on the mice (s) }\end{array}$ & SD \\
\hline Control & $23.08(\mathrm{a})^{*}$ & 1.65 \\
400 & $5.15(\mathrm{~b})$ & 3.28 \\
800 & $1.18(\mathrm{c})$ & 1.36 \\
1000 & 0.00 (d) & 0.00 \\
\hline
\end{tabular}

* Means followed by the same letter in a columm are not significantly different at $P=0.05$. 
Table 2 | Number of live Aedes aegypti adults after application of different rhamnolipids concentrations: control, 400, 800, and 100 mg/L.

\begin{tabular}{lcccc}
\hline $\begin{array}{l}\text { Rhamnolipids } \\
\text { concentration (mg.L-1) }\end{array}$ & $\begin{array}{c}\text { Initial number of } \\
\text { mosquitoes }\end{array}$ & $\begin{array}{c}\text { Average number of } \\
\text { live mosquitoes }\end{array}$ & Deviation & $\%$ of elimination \\
\hline Control & 20 & 18.33 & 1.53 & 8 \\
400 & 20 & 2.67 & 0.58 & 87 \\
800 & 20 & 1.33 & 0.58 & 100 \\
1000 & 20 & 0.00 & 0.00 & 93 \\
\hline
\end{tabular}

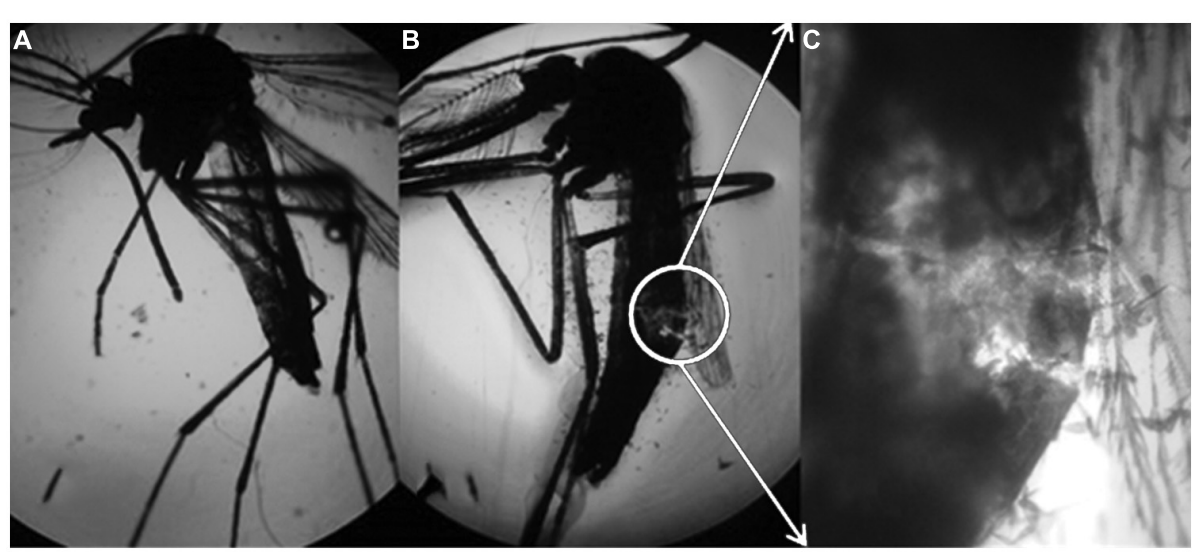

FIGURE 5 | (A) Aedes aegypti subjected to the control treatment (enhanced 50x), (B) A. aegypti subjected to the solution containing $1000 \mathrm{mg} / \mathrm{L}$ of rhamnolipids (enhanced 50x) and (C) expansion of figure (B) enhanced 100x.

siphon position during gas exchange was the cause of A. aegyptilarval deaths. This is in agreement with that reported by Christophers (1960).

The air pockets in the trachea and tracheal trunks of A. aegypti larvae have a specific gravity close to that of water, which facilitates their ascent to the surface (Christophers, 1960).

The apex of the respiratory siphon is strongly hydrophobic, and secretions produced by the peri-spiracular glands are responsible for forming a non-wetting region when the structure is open and in contact with the surface (Christophers, 1960). Rhamnolipids likely interfere in this hydrophobic region, changing the wettability of the respiratory siphon and allowing water to flow in from the spiracular opening. Consequently, the hydrostatic balance is altered, which leads to difficulty returning to the surface. Furthermore, there is a greater energetic cost during transit due to the need for active swimming.

According to Davis et al. (2013), compounds produced by microorganisms are related to the feeding behavior of insects and may be powerful repellents. Verhulst et al. (2009) reported that odors produced by $P$. aeruginosa are not attractive to the mosquito species Anopheles gambiae.

The present study raises the hypothesis that the characteristic odor of rhamnolipids is recognized by A. aegypti adults as being unfavorable as a food source, thus leading to repellent behavior.

Rhamnolipids decreased the incidence of adult mosquitoes landing on mice and reduced the number of biting attempts.
Rhamnolipids led to breakup of the mosquito cuticle, leading to death. According to Kim et al. (2011), di-rhamnolipids act by thinning the cuticle in aphids. Dehydration of adjacent cell membranes also occurs, which separates cellular components and results in death.

Kamal etal. (2012) reported insecticidal activity of rhamnolipids against Rhyzopertha dominica and hypothesized that this biosurfactant acts on cuticular waxes and inter segmental membranes, which may also occur in A. aegypti.

Based on the results obtained in this study, rhamnolipids can replace currently used insecticides (e.g., temephos and pyrethroids). In addition to $A$. aegypti resistance against these insecticides, these chemicals are harmful to the environment and can lead to human health problems.

On the contrary rhamnolipids have been reported to be environmentally friendly and have low toxicity, which makes them suitable substitutes for chemical insecticides.

The rhamnolipids produced by $P$. aeruginosa LBI $2 \mathrm{~A} 1$ have insecticidal activity against larvae and adults of $A$. aegypti and can be used as a repellent against mosquitoes. Therefore this microbial metabolite may be a new weapon to combat dengue and other arboviruses transmitted by $A$. aegypti.

\section{ACKNOWLEDGMENT}

We thank Fundação de Amparo a Pesquisa do Estado de São Paulo (FAPESP), for fellowships and financial support (Process 2011/15345-8). 


\section{REFERENCES}

Awada, S. M., Spendlove, R. S., and Awada, M. (2005). Microbial Biosurfactants as Agents for Controlling Pests. CA Patent Application CA 2566864.

Banat, I. M., Makkar, R. S., and Cameotra, S. S. (2000). Potential commercial application of microbial surfactants. Appl. Microbiol. Biotechnol. 53, 495-508. doi: $10.1007 /$ s002530051648

Chavasse, D. C., and Yap, H. H. (1997). Chemical Methods for the Control of Vectors and Pests of Public Health Importance. Geneva: World Health Organization.

Christophers, S. R. (1960). Aedes aegypti (L.), The Yellow Fever Mosquito. Its Life History, Bionomics, and Structure. New York: Cambridge University Press.

Davis, T. S., Crippen, T. L., Hofstetter, R. W., and Tomberlin, J. K. (2013). Microbial volatile emissions as insect semiochemicals J. Chem. Ecol. 39, 840-859. doi: 10.1007/s10886-013-0306-Z

Desai, J. D., and Banat, I. M. (1997). Microbial production of surfactants and their commercial potential. Microbiol. Mol. Biol. Rev. 61, 47-64.

Eisen, L., Moore, C. G. (2013). Aedes (Stegomyia) aegypti in the continental United States: a vector at the cool margin of its geographic range. J. Med. Entomol. 50, 467-478. doi: 10.1603/ME12245

Eldridge, B. F. (2005). "Mosquitoes, the culicidae," in Biology of Disease Vectors, 2nd Edn. ed. W. H. Marquardt (Burlington: Elsevier Academic), 95-113.

Garelli, F. M., Espinosa, M. O., and Gürtler, R. E. (2013). Spatial analysis of Aedes aegypti immatures in Northern Argentina: clusters and temporal instability. Acta Trop. 128, 461-467. doi: 10.1016/j.actatropica.2013.07.019

Kamal, A., Shaik, A. B., Kumar, C. G., Mongolla, P., Rani, P. U., Krishna, K. V., etal. (2012). Metabolic profiling and biological activities of bioactive compounds produced by Pseudomonas sp. Strain ICTB-745 isolated from Ladakh, India. J. Microbiol. Biotechnol. 22, 69-79. doi: 10.4014/jmb.1105. 05008

Kim, S. K., Kim, Y. C., Lee, S., Kim, J. C., Yun, M. Y., and Kim, I. S. (2011). Insecticidal activity of rhamnolipids isolated from Pseudomonas sp. EP-3 against Green Peach Aphid (Myzus persicae). J. Agric. Food Chem. 59, 934-938. doi: 10.1021/jf104027x

Kourí, G., Pelegrino, J. L., Munster, B. M., and Guzmán, M. G. (2007). Sociedad, economía,inequidades y dengue. Rev. Cubana Med. Trop. 59, 177-185.

Kroeger, A., and Nathan, M. B. (2006). Dengue: setting the global research agenda. Thelancet 368, 2193-2195.

Löwenberg Neto, P. L., and Navarro-Silva, M. A. (2004). Development, longevity, gonotrophic cycle and oviposition of Aedes albopictus Skuse (Diptera: Culicidae) under cyclic temperatures. Neotrop. Entomol. 33, 29-33. doi: 10.1590/S1519566X2004000100006

Mittal, P. K. (2003). Biolarvicides in vector control: challenges and prospects. J. Vector Borne Dis. 40, 20-32.

Müller, M. M., Hörmann, B., Syldatk, C., and Hausmann, R. (2010). Pseudomonas aeruginosa $\mathrm{PAO} 1$ as a model for rhamnolipids production in bioreactor systems. Appl. Microbiol. Biotechnol. 87, 167-174. doi: 10.1007/s00253-010-2513-7

Rahman, P. K. S. M., and Gakpe, E. (2008). Production, characterization and application of biosurfctants - reviw. Biotechnology 7, 360-370. doi: 10.3923/biotech.2008.360.370
Rahman, P. K. S. M., Pasirayi, G., Auger, V., and Ali, Z. (2010). Production of rhamnolipids biosurfactants by Pseudomonas aeruginosa DS10-129 in a microfluidic bioreactor. Biotechnol. Appl. Biochem. 55, 45-52. doi: 10.1042/BA20090277

Rogers, D. J., Suk, J. E., and Semenza, J. C. (2014). Using global maps to predict the risk of dengue in Europe. Acta Trop. 129, 1-14. doi: 10.1016/j.actatropica.2013.08.008

Sekhon Randhawa, K. K., and Rahman, P. K. S. M. (2014). Rhamnolipid biosurfactants-past, present, and future scenario of global market. Front. Microbiol. 5:454. doi: 10.3389/fmicb.2014.00454

Sokal, R. R., and Rohlf, F. J. (1995). Biometry: The Principles and Pratices of Statistics in Biological Research, 3rd Edn. New York: W. H. Freeman.

Tsai, J., Chokephaibulkit, K., Chen, P., Liu, L., Hsiao, H., Lo, Y., et al. (2013). Role of cognitive parameters in dengue hemorrhagic fever and dengue shock syndrome. J. Biomed. Sci. 20, 88. doi: 10.1186/1423-0127-20-88

Vatsa, P., Sanchez, L., Clement, C., Baillieul, F., and Dorey, S. (2010). Rhamnolipid biosurfactants as new players in animal and plant defense against microbes. Int. J. Mol. Sci. 11, 5095-5108. doi: 10.3390/ijms11125095

Verhulst, N. O., Beijleveld, H., Knols, B. G., Takken, W., Schraa, G., Bouwmeester, H. J., et al. (2009). Cultured skin microbiota attracts malaria mosquitoes. Malar. J. 8, 302. doi: 10.1186/1475-2875-8-302

Vontas, J., Kioulos, E., Pavlidi, N., Morou, E., Della Torre, A., and Ranson, H. (2012). Insecticide resistance in the major dengue vectors Aedes albopictus and Aedes aegypti. Pestic. Biochem. Physiol. 104, 126-131. doi: 10.1016/j.pestbp.2012.05.008

Walton, W. E., and Mulla, M. S. (1992). "Impact and fates of microbial pest control agents in the aquatic environment," in Dispersal of Living Organisms into Aquatic Ecosystems, eds A. Rosenfield and R. Mann (College Park, MD: Maryland Sea Grant College, University of Maryland).

World Health Organization. (2009). Dengue and Dengue Haemorrhagic Fever [Internet]. [Place Unknown] Fact Sheet 117. Available at: http://www.who.int/media centre/factsheets/fs117/en/ [accessed November 05, 2014].

Conflict of Interest Statement: The authors declare that the research was conducted in the absence of any commercial or financial relationships that could be construed as a potential conflict of interest.

Received: 27 November 2014; accepted: 23 January 2015; published online: 16 February 2015.

Citation: Silva VL, Lovaglio RB, Von Zuben CJ and Contiero J (2015) Rhamnolipids: solution against Aedes aegypti? Front. Microbiol. 6:88. doi: 10.3389/fmicb.2015.00088 This article was submitted to Microbiotechnology, Ecotoxicology and Bioremediation, a section of the journal Frontiers in Microbiology.

Copyright (C) 2015 Silva, Lovaglio, Von Zuben and Contiero. This is an open-access article distributed under the terms of the Creative Commons Attribution License (CC BY). The use, distribution or reproduction in other forums is permitted, provided the original author(s) or licensor are credited and that the original publication in this journal is cited, in accordance with accepted academic practice. No use, distribution or reproduction is permitted which does not comply with these terms. 